\title{
Efficacy of endoscopic treatments for acute esophageal variceal bleeding in cirrhotic patients: systematic review and meta- analysis
}

\section{다)(1) $(-)$}

\author{
Authors \\ Fernanda de Quadros Onofrio¹, Julio Carlos Pereira-Lima', Felipe Marquezi Valença , André Luis Ferreira Azeredo-da- \\ Silva $^{2}$, Airton Tetelbom Stein ${ }^{3}$
}

Institutions

1 Department of Gastroenterology and Hepatology, Santa Casa Hospital, Federal University of Health Sciences of Porto Alegre (UFCSPA), Porto Alegre, Brazil

2 Department of Internal Medicine, Santa Casa Hospital/ Federal University of Health Sciences of Porto Alegre (UFCSPA), Porto Alegre, Brazil

3 Department of Public Health, Federal University of Health Sciences of Porto Alegre (UFCSPA), Porto Alegre, Brazil

submitted 18.12.2018

accepted after revision 4.4.2019

Bibliography

DOI https://doi.org/10.1055/a-0901-7146 |

Endoscopy International Open 2019; 07: E1503-E1514

(c) Georg Thieme Verlag KG Stuttgart · New York

elSSN 2196-9736

Corresponding author

Fernanda de Quadros Onofrio, Rua São Francisco, 469/

1203, postal code 90620-070, Porto Alegre, Brazil

Fax: +55-51-30225794

fqonofrio@gmail.com

Supplementary Material

Online content viewable at:

https://doi.org/10.1055/a-0901-7146

\section{ABSTRACT}

Background and aim Guidelines recommend use of ligation and vasoactive drugs as first-line therapy and as grade A evidence for acute variceal bleeding (AVB), although Western studies about this issue are lacking.

Methods We performed a systematic review and meta-analysis of randomized controlled trials (RCT) to evaluate the efficacy of endoscopic treatments for AVB in patients with cirrhosis. Trials that included patients with hepatocellular carcinoma, use of portocaval shunts or esophageal resection, balloon tamponade as first bleeding control measure, or that received placebo or elective treatment in one study arm were excluded.

Results A total of 8382 publications were searched, of which 36 RCTs with 3593 patients were included. Ligation was associated with a significant improvement in bleeding control (relative risk [RR] 1.08; 95\% confidence interval [CI] $1.02-1.15$ ) when compared to sclerotherapy. Sclerotherapy combined with vasoactive drugs showed higher efficacy in active bleeding control compared to sclerotherapy alone (RR 1.17; $95 \% \mathrm{Cl} 1.10-1.25)$. The combination of ligation and vasoactive drugs was not superior to ligation alone in terms of overall rebleeding (RR 2.21; $95 \% \mathrm{Cl} 0.55-$ 8.92 ) and in-hospital mortality ( $R R \quad 1.97 ; 95 \% \mathrm{Cl} 0.78-$ 4.97). Other treatments did not generate meta-analysis. Conclusions This study showed that ligation is superior to sclerotherapy, although with moderate heterogeneity. The combination of sclerotherapy and vasoactive drugs was more effective than sclerotherapy alone. Although current guidelines recommend combined use of ligation with vasoactive drugs in treatment of esophageal variceal bleeding, this study failed to demonstrate the superiority of this combined treatment.

\section{Introduction}

Bleeding from gastroesophageal varices is the most common life-threatening complication in patients with cirrhosis, being associated with mortality rates from $10 \%$ to $50 \%$ per episode $[1,2]$. More than half of patients who survive the first episode suffer from recurrent bleeding within 1 year $[3,4]$. Management of acute variceal bleeding (AVB) remains a clinical challenge with high mortality, in spite of standardization in supportive and new therapeutic treatments in the last two decades [5]. 
A beneficial effect on survival has been observed in parallel with introduction of drugs that are capable of decreasing portal pressure, optimization of endoscopic therapy, and use of antibiotics and interventional radiologic procedures. During the same period, the 6 -week mortality rate has decreased from approximately $40 \%$ to $15 \%[5,6]$.

Although overall survival has improved in recent years, mortality is still closely related to failure to control the initial bleeding or early rebleeding, which occurs in up to $30 \%$ to $40 \%$ of patients within the first 5 days after the index bleeding episode $[5,6]$. As a consequence, many patients with cirrhosis and AVB still suffer from failure to control bleeding and most of them die very early [2]. Therapeutic options include vasoactive drugs such as somatostatin, octreotide, and terlipressin; endoscopic treatments such as sclerotherapy and band ligation; and most recently, radiologic interventions, such as early-TIPS (transjugular intrahepatic portosystemic shunt) placement. Therefore, the goal of this study was to evaluate the efficacy and safety of the most-used endoscopic treatments for controlling AVB.

\section{Methods}

A meta-analysis and systematic review of published randomized controlled trials (RCTs) were carried out.

\section{Search strategy}

Medline (PubMed), Embase, Cochrane library and manual searches were combined and last performed on 16 March 2018. Key search terms were "esophageal and gastric varices," "esophageal varices," "esophageal varix," "oesophageal varices," "oesophageal varix," "esophagogastric varices," "esophagogastric varix," "gastroesophageal varices," "gastroesophageal varix," "oesophagogastric varices," "oesophagogastric varix," “oesophago-gastric varices," "oesophago-gastric varix," "esophagogastric varices," "esophago-gastric varix," upper gastrointestinal bleeding," "bleeding, upper gastrointestinal," "upper digestive haemorrhage," "upper digestive hemorrhage," "upperdigestive tract haemorrhage," "upper digestive tract hemorrhage," "uppergastrointestinal haemorrhage," "upper gastrointestinal hemorrhage, "upper gastrointestinal tract bleeding," "variceal bleeding," "esophagus varices bleeding," "esophagus bleeding varix," "esophagus varices haemorrhage," "esophagus varices hemorrhage," and "esophagus varix bleeding”. MeSH terms and free-text terms, as well as variation of root words were searched. Terms were combined within each database. The study has been registered in PROSPERO database under code CRD42017058139.

\section{Criteria for inclusion and exclusion of studies}

Only RCTs were included. To reduce the risk of bias, strict inclusion and exclusion criteria were defined prior to literature search. To be considered, a study had to include patients exclusively with cirrhosis, patients with acute variceal bleeding, have more than 10 patients in each arm, include only adults, and include treatments performed in the first 24 to 48 hours after bleeding. Studies were excluded if they included patients with hepatocellular carcinoma or other malignancies, use of porto- caval shunts or esophageal resection, recent use of balloon tamponade as first bleeding control measure, placebo or elective treatment in one study arm. When two publications existed covering the same study population, only the most recent was taken into account.

\section{Endpoints}

Endpoints were defined prior to the beginning of the meta-analysis. Main endpoints were treatment efficacy for bleeding control and in-hospital mortality. Secondary endpoints were rate of rebleeding from active bleeders at initial endoscopy, rate of overall rebleeding, rate of overall mortality, and rate of adverse events (AEs) related to each treatment.

\section{Data extraction and assessment of quality}

Two reviewers independently abstracted data from included articles (F.Q.O. and F.M.V.). Disagreements were resolved by consensus of all authors. Extracted information included patient population characteristics, intervention characteristics, comparator characteristics, outcomes assessed, and study quality. The latter used the framework suggested by the Cochrane Handbook for Systematic Reviews of Interventions (version 5.1.0), with evaluation of the following trial characteristics: random sequence generator method, concealment of treatment allocation, blinding of participants and personnel, blinding of outcome assessment, and for selective reporting [7]. Intention-to-treat analysis and the funding source of the studies were also assessed. The GRADE methodology [7] was used to define risk of bias for each of the outcomes that had available data.

\section{Sources of support}

This systematic review and meta-analysis was not supported by any grant.

\section{Statistical analysis}

We performed direct random effects model meta-analyses of head-to-head comparisons for pooling effect sizes of reported comparisons and outcomes whenever enough data were provided in published studies. No data imputation was done, and studies not reporting information that allowed treatmenteffect calculation were not included in the meta-analyses. Summary effect for binary outcomes was calculated from risk ratios. Heterogeneity was evaluated with the inconsistency test proposed by Higgins $\left(\mathrm{I}^{2}\right)$, where values below $25 \%$ were considered as low heterogeneity, and above $75 \%$, high heterogeneity [ 8 , 9]. Publication bias was assessed with funnel plots of comparisons with seven or more studies. Meta-analyses were carried out in Review Manager 5.3 (The Nordic Cochrane Centre, The Cochrane Collaboration, 2011). Prediction intervals were calculated with the Paule-Mandel estimator for tau squared and the Hartung-Knapp adjustment for random effects model. Prediction interval calculations were done with the software " $R$ " (v 3.5.0) and package “Meta” (v 4.9-4) [10]. 


\section{Results}

\section{Studies selection}

A total of 8382 citations were screened, of them 6691 were evaluated after duplicates were removed ( $\mathbf{F i g} \mathbf{1}$ ). Of these, 69 were selected for full-text evaluation. Among them, only 36 randomized trials [11-46] were identified that fulfilled the inclusion criteria ( $\triangleright$ Table 1 ): seven studies compared sclerotherapy with vasoactive drugs (two studies with somatostatin, three studies with octreotide, one with terlipressin and one with vasopressin plus nitroglycerin); two studies compared ligation with vasoactive drugs (one with octreotide and one with somatostatin); one study compared ligation with cyanoacrylate injection; 10 studies compared sclerotherapy with ligation; seven studies compared sclerotherapy with the combination of sclerotherapy and vasoactive drugs (six with octreotide and one with somatostatin); five studies compared ligation with sclerotherapy and ligation; two studies compared ligation with ligation and vasoactive drugs (one with somatostatin and with octreotide); one study compared sclerotherapy and octreotide with octreotide alone; and one study compared ligation and octreotide with octreotide alone.

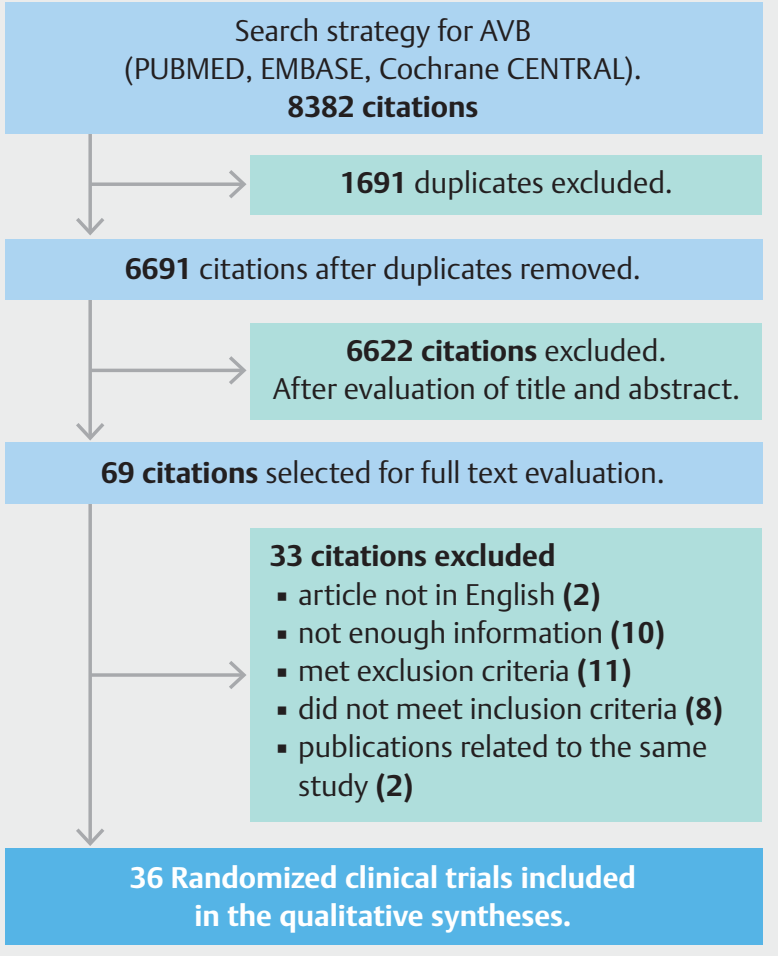

Fig. 1 Study selection flowchart.

- Table 1 Demographic data from included studies.

\begin{tabular}{|c|c|c|c|c|c|c|c|}
\hline Author (year) & $\begin{array}{l}\text { Patients, } \\
\text { n [a/b] }\end{array}$ & $\begin{array}{l}\text { Mean age, } \\
\text { years }\end{array}$ & $\begin{array}{l}\text { Men, } \\
n \%\end{array}$ & $\begin{array}{l}\text { Main cause of cirrhosis, } \\
n[a / b]\end{array}$ & $\begin{array}{l}\text { Child- } \\
\text { pugh class } \\
\text { c } \%[\mathrm{a} / \mathrm{b}]\end{array}$ & $\begin{array}{l}\text { Active } \\
\text { bleeding } \\
\%[a / b]\end{array}$ & $\begin{array}{l}\text { Follow-up for ini- } \\
\text { tial control of } \\
\text { bleeding (hours) }\end{array}$ \\
\hline \multicolumn{8}{|l|}{ Intervention $\mathbf{a x b}$} \\
\hline \multicolumn{8}{|c|}{ Sclerotherapy x VP + NG } \\
\hline Westaby (1989) & $33 / 31$ & 54.2 & 56.3 & Alcohol 13/alcohol 22 & $36 / 32$ & $100 / 100$ & 12 \\
\hline \multicolumn{8}{|c|}{ Sclerotherapy x somatostatin } \\
\hline Shields (1992) & $41 / 39$ & 58 & 67.5 & Alcohol 26/alcohol 28 & $41 / 64$ & $61 / 69$ & 120 \\
\hline Planas (1994) & $35 / 35$ & 57 & 71.4 & Alcohol 28/alcohol 22 & $34 / 34$ & $48.5 / 51.4$ & 48 \\
\hline \multicolumn{8}{|c|}{ Sclerotherapy $\mathrm{x}$ octreotide } \\
\hline Sung (1993) & $49 / 49$ & 55.7 & 84.7 & HBV 32/HBV 36 & $42 / 43$ & $37 / 51$ & 48 \\
\hline Sivri (2000) & $36 / 30$ & 47 & 24.2 & Viral 8/viral 14 & $53 / 55$ & $100 / 100$ & 6 \\
\hline Bildozola (2000) & $37 / 39$ & 52.6 & 78.9 & Alcohol 27/alcohol 28 & $8 / 13$ & $48.6 / 38.5$ & 12 \\
\hline \multicolumn{8}{|c|}{ Sclerotherapy $\mathrm{x}$ terlipressin } \\
\hline Escorsell (2000) & $114 / 105$ & 55.5 & 72.1 & Alcohol 47/alcohol 41 & $31 / 32$ & $42.9 / 35.2$ & 48 \\
\hline \multicolumn{8}{|c|}{ Sclerotherapy x sclerotherapy + octreotide } \\
\hline Besson (1995) & $101 / 98$ & 56 & 76.4 & Alcohol 93/alcohol 89 & $46 / 26$ & $46.5 / 428$ & 24 \\
\hline Shiha (1996) & $96 / 93$ & 49.6 & 81.5 & HCV $45 / H C V ~ 44$ & $12 / 15$ & $100 / 100$ & 168 \\
\hline Faraoqi (2000) & $69 / 72$ & & & & & $100 / 100$ & Not clearly stated \\
\hline Zuberi (2000) & $35 / 35$ & 38.5 & 80.0 & HBV 28/HBV 26 & $0 / 0$ & $100 / 100$ & 24 \\
\hline
\end{tabular}


- Table 1 (Continuation)

\begin{tabular}{|c|c|c|c|c|c|c|c|}
\hline Author (year) & $\begin{array}{l}\text { Patients, } \\
\mathrm{n}[\mathrm{a} / \mathrm{b}]\end{array}$ & $\begin{array}{l}\text { Mean age, } \\
\text { years }\end{array}$ & $\begin{array}{l}\text { Men, } \\
\text { n \% }\end{array}$ & $\begin{array}{l}\text { Main cause of cirrhosis, } \\
\mathrm{n}[\mathrm{a} / \mathrm{b}]\end{array}$ & $\begin{array}{l}\text { Child- } \\
\text { pugh class } \\
\text { c } \%[a / b]\end{array}$ & $\begin{array}{l}\text { Active } \\
\text { bleeding } \\
\%[a / b]\end{array}$ & $\begin{array}{l}\text { Follow-up for ini- } \\
\text { tial control of } \\
\text { bleeding (hours) }\end{array}$ \\
\hline Shah (2005) & $54 / 51$ & 49.8 & 64.8 & Viral 52/viral 49 & $26 / 21$ & $44.4 / 45$ & Not clearly stated \\
\hline Morales (2007) & $28 / 40$ & 51.8 & 66.2 & HCV 14/HCV + alcohol 11 & $36 / 60$ & $46 / 65$ & Not clearly stated \\
\hline \multicolumn{8}{|c|}{ Sclerotherapy $x$ sclerotherapy + somatostain } \\
\hline Avgerinos (1997) & $101 / 104$ & 58.6 & 70.7 & Alcohol 59/alcohol 61 & $28 / 25$ & $40.3 / 26.7$ & Not clearly stated \\
\hline \multicolumn{8}{|c|}{ Octreotide + sclerotherapy $x$ octreotide } \\
\hline Patsanas (2002) & $15 / 15$ & 51 & 70.0 & Alcohol 8/viral 5 & $60 / 53$ & $33 / 43$ & 120 \\
\hline \multicolumn{8}{|c|}{ Sclerotherapy $\mathrm{x}$ ligation } \\
\hline Stiegmann (1992) & $65 / 64$ & 52.0 & 80.6 & Alcohol 52/alcohol 53 & $20 / 19$ & $20 / 22$ & 8 \\
\hline Laine (1993) & $38 / 39$ & 46.0 & 75.3 & Alcohol 30/alcohol 31 & $12,8 / 34,2$ & $23 / 24$ & Not clearly stated \\
\hline Gimson (1993) & $49 / 54$ & 51.4 & 55.3 & Alcohol 24/alcohol 25 & $24 / 28$ & $23 / 39$ & 12 \\
\hline Lo (1995) & $59 / 61$ & 55.5 & 80.8 & Viral 43/viral 41 & $47 / 49$ & $25 / 29$ & 72 \\
\hline Hou (1995) & $67 / 67$ & 60.6 & 79.9 & Viral $47 /$ viral 43 & $34 / 43$ & $23 / 29.8$ & 24 \\
\hline Lo (1997) & $34 / 37$ & 54.0 & 86.1 & HCV $11+$ alcohol 11/HBV 15 & $59 / 59$ & $100 / 100$ & 72 \\
\hline Shafqat (1998) & $30 / 28$ & 52.0 & 63.8 & HCV 21/HCV 18 & $13 / 11$ & $93 / 86$ & 12 \\
\hline De la Peña (1999) & $46 / 42$ & 59.0 & 72.7 & Alcohol 29/alcohol 29 & $28 / 24$ & $47.8 / 42.8$ & Not clearly stated \\
\hline Luz (2011) & $50 / 50$ & 52.3 & 72.0 & $\begin{array}{l}\text { Alcohol } 19+\text { virus } 19 / \\
\text { alcohol } 17\end{array}$ & $40 / 30$ & $10 / 20$ & 120 \\
\hline Sahu (2014) & $103 / 111$ & & & & & & Not clearly stated \\
\hline \multicolumn{8}{|c|}{ Ligation $\mathrm{x}$ octreotide } \\
\hline Ximing (2013) & & & & & & & Not clearly stated \\
\hline \multicolumn{8}{|c|}{ Ligation $\mathrm{x}$ somatostatin } \\
\hline Chen (2006) & $62 / 63$ & 53.2 & 76.0 & Alcohol 24/alcohol 29 & $29 / 28$ & $27.4 / 20.6$ & 48 \\
\hline \multicolumn{8}{|c|}{ Ligation $x$ cyanoacrylate injection } \\
\hline Ljubicic (2011) & $21 / 22$ & 58 & 72.1 & Alcohol/alcohol & $19 / 41$ & $52.4 / 90.9$ & 24 \\
\hline \multicolumn{8}{|c|}{ Ligation $\mathrm{x}$ ligation + sclerotherapy } \\
\hline Laine (1996) & $20 / 21$ & 47 & 73.2 & Alcohol 16/alcohol 15 & $45 / 43$ & $20 / 19$ & Not clearly stated \\
\hline Saeed (1997) & $25 / 22$ & 53.1 & 91.5 & Alcohol 22/alcohol 16 & $16 / 41$ & $28 / 18$ & Not clearly stated \\
\hline Al traif (1999) & $31 / 29$ & 48.8 & 61.7 & HCV $10 / H C V ~ 14$ & $32 / 17$ & $22.5 / 31$ & Not clearly stated \\
\hline Djurdjevic (1999) & $51 / 52$ & 55.6 & 61.2 & Alcohol 25/alcohol 28 & $23 / 19$ & $23.5 / 19,2$ & Not clearly stated \\
\hline Mansour (2017) & $60 / 60$ & 0.0 & 65.0 & HCV 52/HCV 52 & $53 / 40$ & & 48 \\
\hline \multicolumn{8}{|c|}{ Ligation + octreotide $\mathrm{x}$ octreotide } \\
\hline Liu (2009) & $51 / 50$ & 41 & 81.2 & & $55 / 48$ & $35.2 / 34$ & 72 \\
\hline \multicolumn{8}{|c|}{ Ligation $\mathrm{x}$ ligation + somatostatin } \\
\hline Sarin (2008) & $24 / 23$ & 43.6 & 74.0 & & & 40.0 & Not clearly stated \\
\hline \multicolumn{8}{|c|}{ Ligation $\mathrm{x}$ ligation + octreotide } \\
\hline Sung (1995) & $47 / 47$ & 57.0 & 71.3 & Hepatitis 29/hepatitis 27 & $40.4 / 42.6$ & $44.7 / 34.0$ & 24 \\
\hline
\end{tabular}






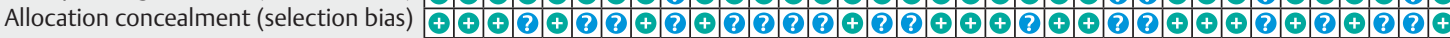

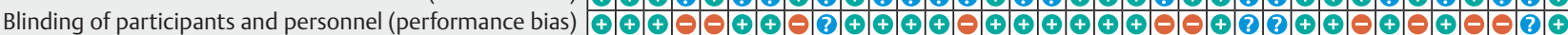

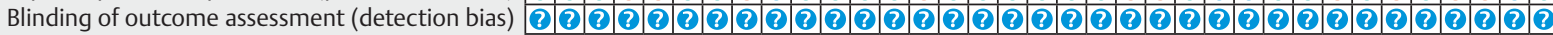



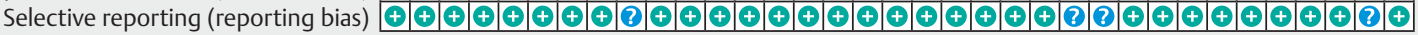

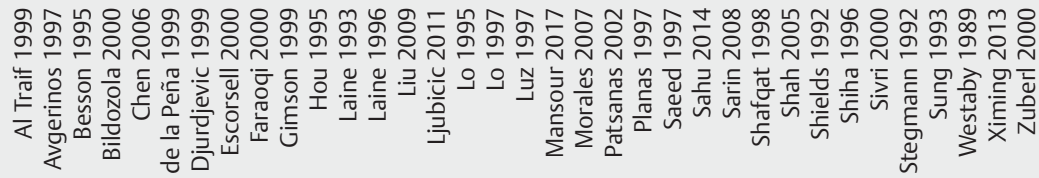

Fig. 2 Risk of bias assessment of included studies. Green circles: low risk of bias for a given quality assessment domain; blue circles: unclear risk of bias for a given quality assessment domain; red circles: high risk of bias for a given quality assessment domain.

\section{Studies characteristics}

Only 32 RCTs had been published as full papers. Four trials were published as abstracts $[32,40,44,45]$. In six studies [11, 23, 24, $31,32,35]$, patients were included only if they had ongoing bleeding at time of initial endoscopy. Alcoholic cirrhosis was the predominant cause of portal hypertension in 18 studies. In contrast, cirrhosis due to viral hepatitis infection was the leading cause in 13 studies (patients from Asia, Brazil, and the Middle East). Otherwise, baseline characteristics of the study populations, such as gender ratio, Child-Pugh class or mean age, were comparable ( $\triangleright$ Table 1 ). Only 11 of the 36 trials described separately the rebleeding rate of the different treatment modalities in active bleeders at the time of endoscopy, i. e., 25 studies analyzed together active and non-active bleeders (Supplementary Table 1 - Supporting Information).

\section{Risk of bias within trials}

The included trials had risk of bias evaluated according to the Cochrane recommendations for meta-analyses and systematic

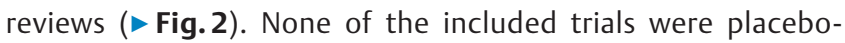
controlled. The randomization-method of the majority of the trials was computer-generated random sequences, with only four trials (abstracts) having no information about randomization. Eighteen trials had low risk for concealment of treatment allocation. Blinding of outcome assessment was not stated in any of the peer-reviewed articles.

Prediction intervals for random effects meta-analyses are presented in $>$ Table 2 .

\section{Risk of bias across trials}

With respect to risk of publication bias, funnel plots were generally symmetrical, which indicates a low probability of publication bias in the present systematic review.

\section{Comparison of sclerotherapy with vasoactive medications}

Sclerotherapy was compared to somatostatin, octreotide, and vasopressin plus nitroglycerin in seven trials. The rate of complications was significantly higher with sclerotherapy (6 trials; relative risk [RR] 2.10; $95 \%$ confidence interval $[\mathrm{Cl}] 1.52$ $\left.2.90 ; P<0.00001 ; I^{2}=0 \%\right)$ when compared to vasoactive drug alone. There was no significant difference in the other analyzed outcomes. The studies by Planas and Escorsell had no specific description of in-hospital mortality, so they were not included in this analysis.

In patients with active bleeding at endoscopy, sclerotherapy was needed in 17 patients to achieve active bleeding control in one of them when compared to vasoactive drug alone (number needed to treat [NNT] $\left.17, \mathrm{I}^{2}=0 \%, P<0.05\right)$.

\section{Comparison of ligation with vasoactive medications}

Only two trials $[38,44]$ compared ligation with vasoactive medications (somatostatin and octreotide). However, the study by Ximing was published as an abstract and did not have enough information to be included in the analysis.

\section{Comparison of sclerotherapy with ligation}

Ligation was associated with significant improvement in bleeding control (10 trials; RR 1.08; Cl 1.02-1.15; $P=0.01 ; I^{2}=49 \%$ ) compared to sclerotherapy ( $\mathbf{F i g . 3}$ ). The heterogeneity was potentially explained by the differences in two identified subgroups: one formed by Lo [19], Hou [21], Lo [24], Squafat [27] and de la Peña [29] (mostly Asian studies) in which ligation was clearly superior to sclerotherapy and another group of five trials (mostly Western trials) in which both techniques had similar results.

Risk of overall rebleeding was statistically significantly higher ( 10 trials; RR $1.4195 \% \mathrm{Cl} 1.03-1.94 ; P=0.03 ; I^{2}=62 \%$ ) with sclerotherapy than with ligation. The high heterogeneity was explained by the same reasons as mentioned above.

Overall mortality was $38 \%$ higher in patients treated with sclerotherapy compared to ligation (9 trials; RR $0.7295 \% \mathrm{Cl}$ $0.54-0.97 ; P=0.03 ; I^{2}=35 \%$ ) ( Fig. 4). Overall mortality was not reported in the study by Laine et al [14].

Rebleeding rate from active bleeders (only 1 trial) could not generate meta-analysis. In-hospital mortality analysis (only 3 trials) had not shown statistical difference.

The rate of complications was significantly lower with ligation (8 trials; RR $0.2995 \% \mathrm{Cl} 0.20-0.44 ; P<0.00001 ; \mathrm{I}^{2}=0 \%$ ) when compared to sclerotherapy. 
- Table 2 Prediction intervals for random-effects models.

\begin{tabular}{|c|c|c|c|}
\hline $\begin{array}{l}\text { Com- } \\
\text { parison }\end{array}$ & Outcome & $\begin{array}{l}\text { Prediction } \\
\text { interval }\end{array}$ & Meta-analysis and prediction interval interpretation \\
\hline \multicolumn{4}{|c|}{ Ligation x sclerotherapy } \\
\hline & $\begin{array}{l}\text { Efficacy of bleed- } \\
\text { ing control }\end{array}$ & 0.91 to 1.29 & $\begin{array}{l}\text { Random effects meta-analysis statistically signiffican but prediction interval indicating } \\
\text { uncertainty on true effect size and direction }\end{array}$ \\
\hline & $\begin{array}{l}\text { Overall } \\
\text { rebleeding }\end{array}$ & 0.25 to 1.99 & $\begin{array}{l}\text { Random effects meta-analysis statistically signiffican but prediction interval indicating } \\
\text { uncertainty on true effect size and direction }\end{array}$ \\
\hline & $\begin{array}{l}\text { In-hospital } \\
\text { mortality }\end{array}$ & Zero to infinity & $\begin{array}{l}\text { No statistically significant differences in random-effects meta-analysis estimate and } \\
\text { prediction interval indicating complete uncertainty on true effect size and direction }\end{array}$ \\
\hline & Overall mortality & 0.33 to 1.57 & $\begin{array}{l}\text { Random effects meta-analysis statistically signiffican but prediction interval indicating } \\
\text { uncertainty on true effect size and direction }\end{array}$ \\
\hline & Complications & 0.18 to 0.47 & $\begin{array}{l}\text { Random effects meta-analysis statistically signifficant and prediction interval indicating } \\
\text { low uncertainty on true effect size and no uncertainty on true effect direction }\end{array}$ \\
\hline \multicolumn{4}{|c|}{ Sclerotherapy $\mathrm{x}$ drug } \\
\hline & $\begin{array}{l}\text { Efficacy of bleed- } \\
\text { ing control }\end{array}$ & 0.99 to 1.17 & $\begin{array}{l}\text { No statistically significant differences in random-effects meta-analysis estimate and } \\
\text { prediction interval indicating low uncertainty on true effect size and direction }\end{array}$ \\
\hline & $\begin{array}{l}\text { Overall } \\
\text { rebleeding }\end{array}$ & 0.71 to 1.06 & $\begin{array}{l}\text { No statistically significant differences in random-effects meta-analysis estimate and } \\
\text { prediction interval indicating low uncertainty on true effect size and direction }\end{array}$ \\
\hline & $\begin{array}{l}\text { Rebleeding from } \\
\text { active bleeders }\end{array}$ & 0.92 to 1.48 & $\begin{array}{l}\text { No statistically significant differences in random-effects meta-analysis estimate and } \\
\text { prediction interval indicating some uncertainty on true effect size and direction }\end{array}$ \\
\hline & $\begin{array}{l}\text { In-hospital } \\
\text { mortality }\end{array}$ & 0.43 to 1.42 & $\begin{array}{l}\text { No statistically significant differences in random-effects meta-analysis estimate and } \\
\text { prediction interval indicating low uncertainty on true effect size and direction }\end{array}$ \\
\hline & Overall mortality & 0.41 to 1.49 & $\begin{array}{l}\text { No statistically significant differences in random-effects meta-analysis estimate and } \\
\text { prediction interval indicating some uncertainty on true effect size and direction }\end{array}$ \\
\hline & Complications & 1.34 to 3.29 & $\begin{array}{l}\text { Random effects meta-analysis statistically signifficant and prediction interval indicating } \\
\text { some uncertainty on true effect size and no uncertainty on true effect direction }\end{array}$ \\
\hline
\end{tabular}

\section{Sclerotherapy + drug $\mathrm{x}$ sclerotherapy}

\begin{tabular}{|c|c|c|c|}
\hline & $\begin{array}{l}\text { Efficacy of bleed- } \\
\text { ing Control }\end{array}$ & 1.04 to 1.31 & $\begin{array}{l}\text { Random effects meta-analysis statistically signifficant and prediction interval indicating } \\
\text { low uncertainty on true effect size and no uncertainty on true effect direction }\end{array}$ \\
\hline & $\begin{array}{l}\text { Overall rebleed- } \\
\text { ing }\end{array}$ & 0.08 to 1.40 & $\begin{array}{l}\text { Random effects meta-analysis statistically signifficant and prediction interval indicating } \\
\text { some uncertainty on true effect size and direction }\end{array}$ \\
\hline & $\begin{array}{l}\text { Rebleeding from } \\
\text { active bleeders }\end{array}$ & 0.02 to 3.45 & $\begin{array}{l}\text { Random effects meta-analysis statistically signiffican but prediction interval indicating } \\
\text { uncertainty on true effect size and direction }\end{array}$ \\
\hline & $\begin{array}{l}\text { In-hospital } \\
\text { mortality }\end{array}$ & 0.52 to 1.32 & $\begin{array}{l}\text { No statistically significant differences in random-effects meta-analysis estimate and } \\
\text { prediction interval indicating low uncertainty on true effect size and direction }\end{array}$ \\
\hline & Overall mortality & 0.64 to 1.28 & $\begin{array}{l}\text { No statistically significant differences in random-effects meta-analysis estimate and } \\
\text { prediction interval indicating low uncertainty on true effect size and direction }\end{array}$ \\
\hline \multicolumn{4}{|c|}{ Ligation x ligation + sclerotherapy } \\
\hline & $\begin{array}{l}\text { Efficacy of bleed- } \\
\text { ing control }\end{array}$ & 0.70 to 1.45 & $\begin{array}{l}\text { No statistically significant differences in random-effects meta-analysis estimate and } \\
\text { prediction interval indicating high uncertainty on true effect size and direction }\end{array}$ \\
\hline & $\begin{array}{l}\text { Overall } \\
\text { rebleeding }\end{array}$ & 0.60 to 1.48 & $\begin{array}{l}\text { No statistically significant differences in random-effects meta-analysis estimate and } \\
\text { prediction interval indicating some uncertainty on true effect size and direction }\end{array}$ \\
\hline & $\begin{array}{l}\text { In-hospital } \\
\text { mortality }\end{array}$ & 0.04 to 13.65 & $\begin{array}{l}\text { No statistically significant differences in random-effects meta-analysis estimate and } \\
\text { prediction interval indicating high uncertainty on true effect size and direction }\end{array}$ \\
\hline & Overall mortality & 0.06 to 14.32 & $\begin{array}{l}\text { No statistically significant differences in random-effects meta-analysis estimate and } \\
\text { prediction interval indicating high uncertainty on true effect size and direction }\end{array}$ \\
\hline & Complications & 0.30 to 0.86 & $\begin{array}{l}\text { Random effects meta-analysis statistically signifficant and prediction interval indicating } \\
\text { low uncertainty on true effect size and no uncertainty on true effect direction }\end{array}$ \\
\hline
\end{tabular}


- Table 2 (Continuation)

\begin{tabular}{|l|l|l|l|}
\hline $\begin{array}{l}\text { Com- } \\
\text { parison }\end{array}$ & Outcome & $\begin{array}{l}\text { Prediction } \\
\text { interval }\end{array}$ & Meta-analysis and prediction interval interpretation \\
\hline \multicolumn{1}{|l|}{ Ligation $\mathbf{x}$ drug } & & \\
\hline & $\begin{array}{l}\text { Efficacy of bleed- } \\
\text { ing control }\end{array}$ & 0.98 to 1.88 & $\begin{array}{l}\text { Random effects meta-analysis statistically signifficant and prediction interval indicating } \\
\text { some uncertainty on true effect size and little uncertainty on true effect direction }\end{array}$ \\
\hline $\begin{array}{l}\text { Overall rebleed- } \\
\text { ing }\end{array}$ & Zero to infinity & $\begin{array}{l}\text { No statistically significant differences in random-effects meta-analysis estimate and } \\
\text { prediction interval indicating complete uncertainty on true effect size and direction }\end{array}$ \\
\hline Overall mortality & Zero to infinity & $\begin{array}{l}\text { No statistically significant differences in random-effects meta-analysis estimate and } \\
\text { prediction interval indicating complete uncertainty on true effect size and direction }\end{array}$ \\
\hline Ligation $\mathbf{x}$ ligation + drug & $\begin{array}{l}\text { Overall rebleed- } \\
\text { ing }\end{array}$ & Zero to infinity & $\begin{array}{l}\text { No statistically significant differences in random-effects meta-analysis estimate and } \\
\text { prediction interval indicating complete uncertainty on true effect size and direction }\end{array}$ \\
\hline Overall mortality & 0.15 to 26.64 & $\begin{array}{l}\text { No statistically significant differences in random-effects meta-analysis estimate and } \\
\text { prediction interval indicating low uncertainty on true effect size and direction }\end{array}$ \\
\hline
\end{tabular}

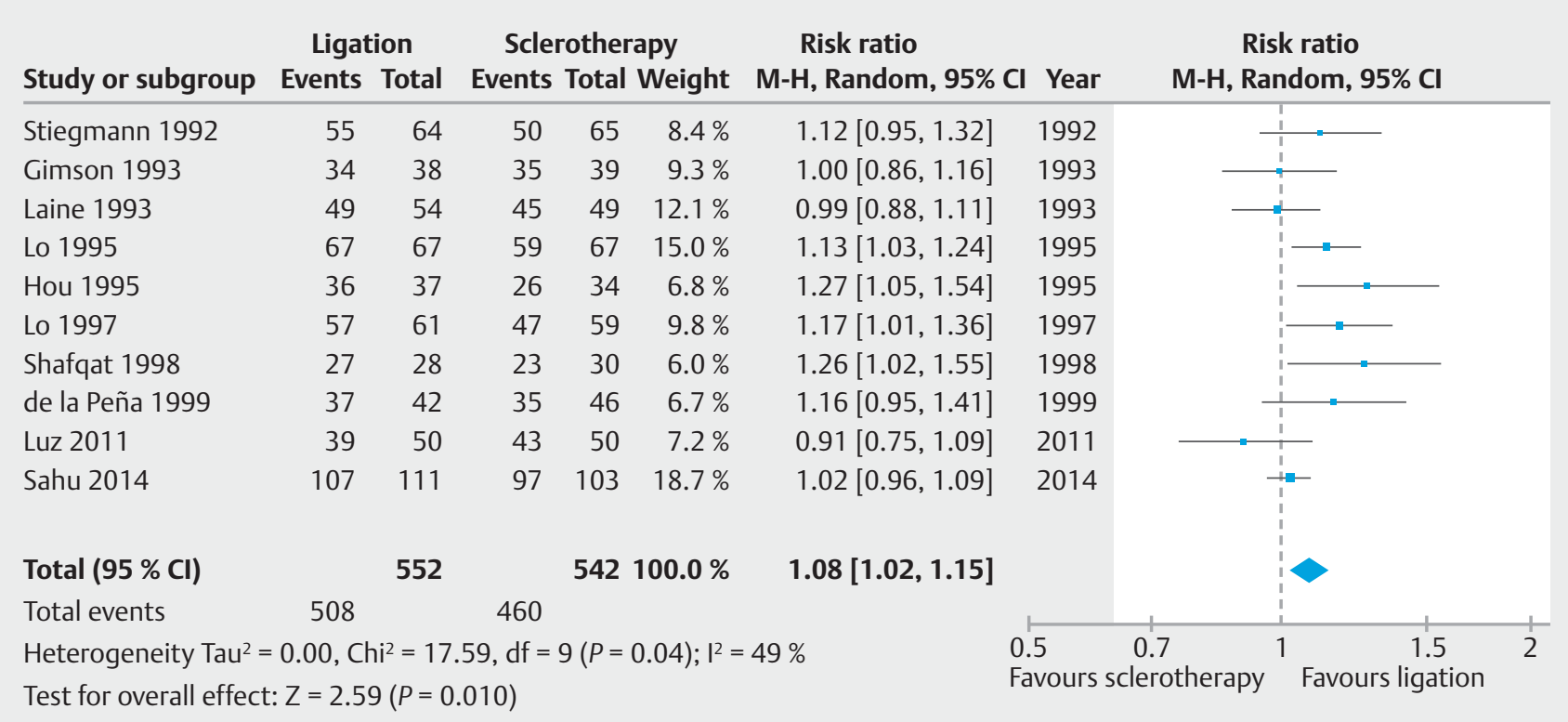

- Fig. 3 Forest plot of risk ratio for efficacy of bleeding control with ligation versus sclerotherapy.

\section{Comparison of sclerotherapy and vasoactive medications with sclerotherapy alone}

Efficacy of bleeding control was $17 \%$ higher with the combination of sclerotherapy and vasoactive drugs in comparison to sclerotherapy alone (7 trials; RR of 1.17 ; $95 \% \mathrm{Cl} 1.10-1.25$; $P<0.00001 ;\left.\right|^{2}=25 \%$ ) (> Fig. 5).

Overall rebleeding was $66 \%$ lower (6 trials, RR 0.34; $95 \% \mathrm{Cl}$ $\left.0.19-0.61 ; P=0.0003 ; I^{2}=42 \%\right)$ with the association of sclerotherapy plus vasoactive drug compared to sclerotherapy alone ( Fig.6).

Risk of rebleeding from active bleeders at initial endoscopy was $73 \%$ lower (4 trials; RR 0.27; $0.12-0.60 ; P=0.001 ; I^{2}=35 \%$ ) with the combination of sclerotherapy and vasoactive drugs compared to sclerotherapy alone ( $\boldsymbol{\text { Fig. }} \mathbf{7}$ ).
In-hospital mortality and overall mortality did not show difference in effect.

Combining sclerotherapy with vasoactive drug in seven patients resulted in control of active bleeding and reduced risk of rebleeding in one patient when compared to sclerotherapy alone (NNT 7, $\mathrm{I}^{2}=0 \%, P<0.05$ ). In addition, the combination of sclerotherapy with vasoactive drug was needed in six patients to reduce rebleeding from active bleeders in one of them when compared to sclerotherapy alone (NNT $-6, \mathrm{I}^{2}=0 \%$, $P<0.05)$. 


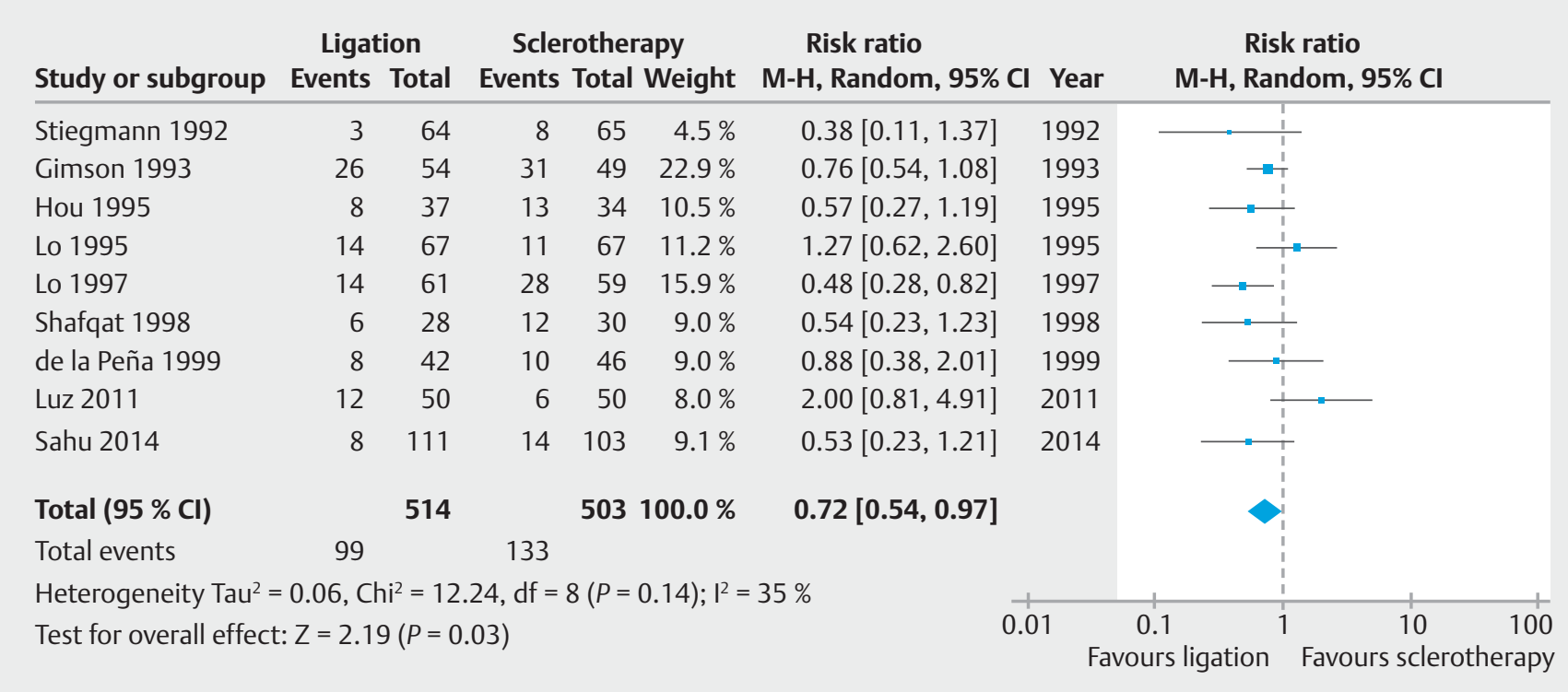

Fig. 4 Forest plot of risk ratio for overall mortality with ligation versus sclerotherapy.

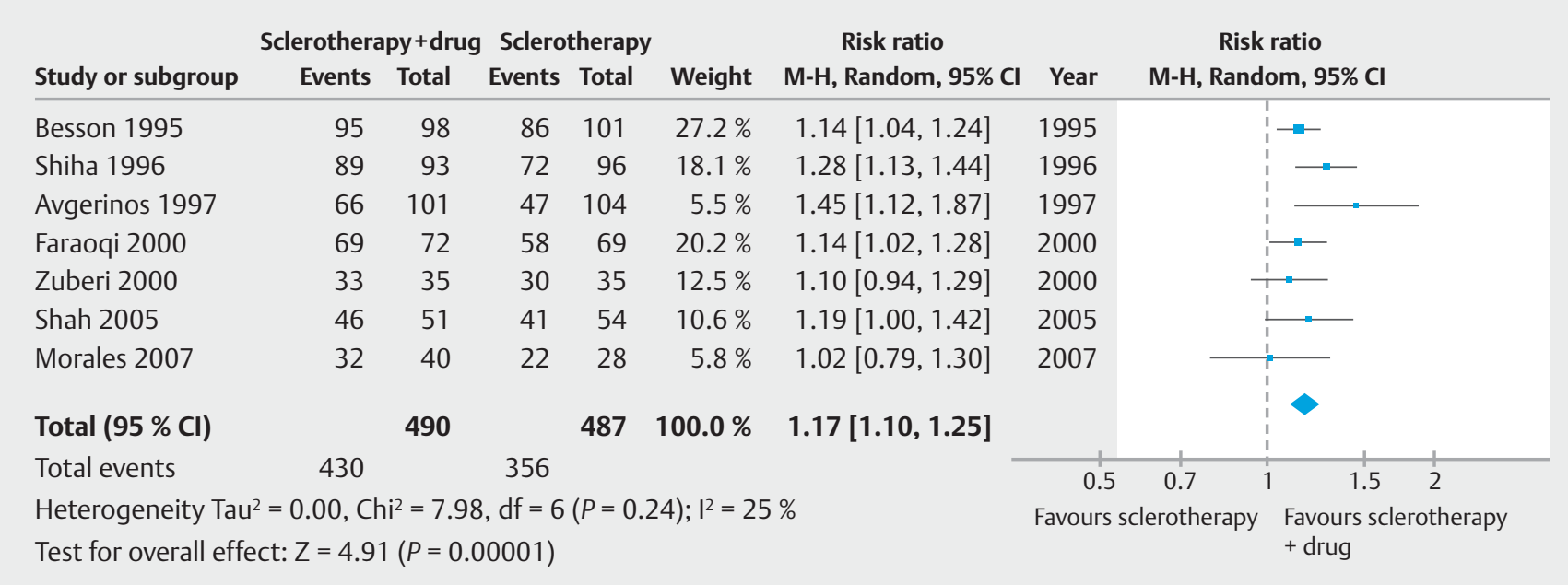

Fig. 5 Forest plot of risk ratio for efficacy of bleeding control with sclerotherapy and vasoactive drug versus sclerotherapy alone.

\section{Comparison of ligation with the combination of ligation and sclerotherapy}

Five trials [22, 26, 28, 30,46] had evaluated ligation versus the combination of ligation and sclerotherapy. Risk of complications was significantly lower with ligation (5 trials, RR 0.58; 95 $\left.\% \mathrm{Cl} 0.39-0.88 ; P=0.01 ; I^{2} 0 \%\right)$ when compared to the combination of ligation and sclerotherapy. However, there were no statistically significant differences among the other analyzed outcomes.

\section{Comparison of ligation with cyanoacrylate injection}

Only one trial [42] evaluated ligation with cyanoacrylate injection and, therefore, could not generate meta-analysis. This trial showed no difference in efficacy of bleeding control, rebleed- ing rate, or mortality rate with cyanoacrylate injection compared with endoscopic ligation.

\section{Comparison of ligation with ligation and vasoactive drugs}

Only two trials evaluated this treatment combination, one with somatostatin and other with octreotide [20,39]. Among the outcomes analyzed, only overall rebleeding ( $>$ Fig.8) and inhospital mortality ( $\mathbf{F i g . 9}$ ) generated meta-analysis, but with no significant statistical difference. 


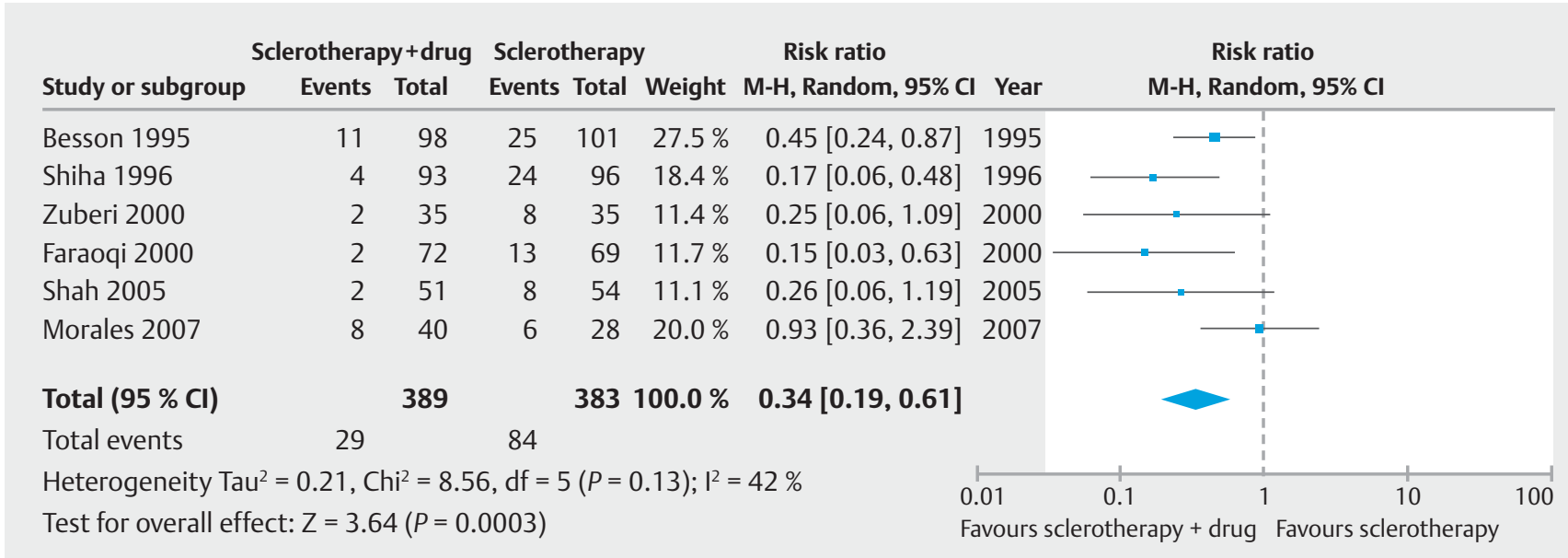

Fig. 6 Forest plot of risk ratio for overall rebleeding with sclerotherapy and vasoactive drug versus sclerotherapy alone.

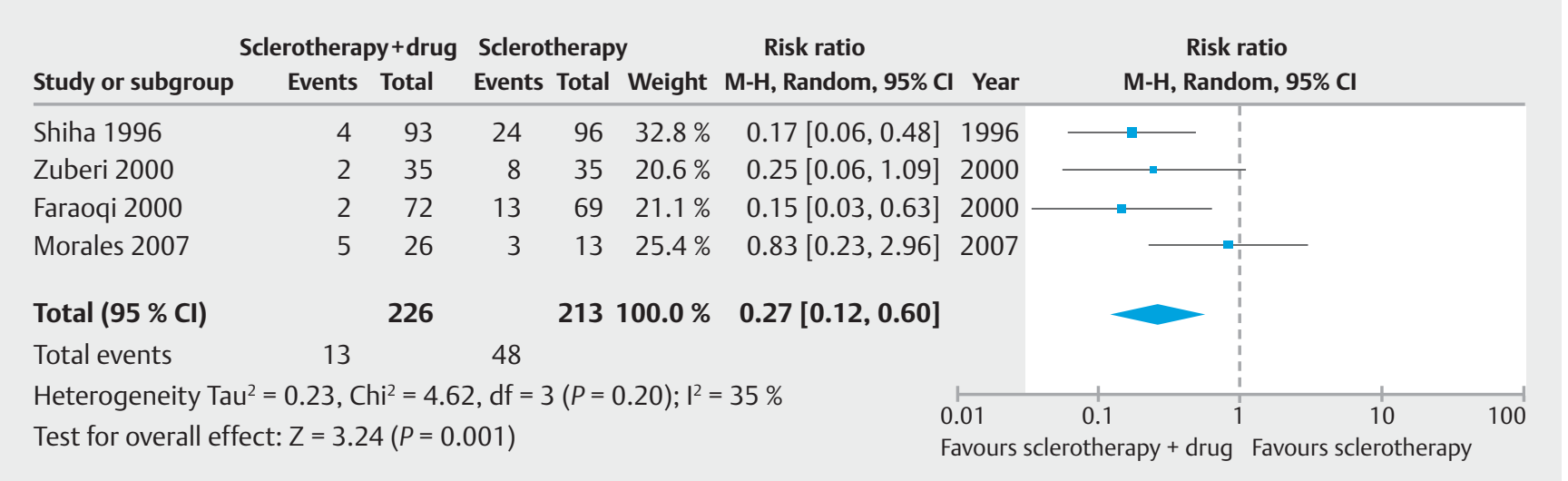

Fig. 7 Forest plot of risk ratio for rebleeding from active bleeders comparing sclerotherapy and vasoactive drug versus sclerotherapy alone.

\section{Discussion}

Thirty-six trials, including 3593 patients, evaluated treatments for AVB control.

Among them, 10 trials compared sclerotherapy with ligation, favoring ligation in terms of efficacy of bleeding control, rebleeding, overall mortality, and rate of complications in a statistically significant fashion. However, this comparison showed a moderate heterogeneity.

The heterogeneity was potentially explained by the differences in two identified subgroups as stated above (results chapter): one formed mostly by Asian studies [19, 21, 24, 27, 29] in which ligation was clearly superior to sclerotherapy and another formed mostly by Western trials $[13-15,43,45]$ in which both techniques had similar results. In the first subgroup of studies, the main cause of cirrhosis was viral and in three of five trials, the sclerosant used was tetradecyl sulfate with $50 \%$ dextrose. In the second subgroup, the majority of patients had cirrhosis secondary to excessive alcohol intake and only one study used tetradecyl sulfate with $50 \%$ dextrose as sclerosant. Moreover, the second subgroup had higher percentages of active bleeders at initial endoscopy in all ligation arms compared to the sclerotherapy arms, which was not noticed in the first subgroup of studies. Prevalence of Child-Pugh $C$ patients was similar in both subgroups.

Although ligation currently is considered the gold standard endoscopic method compared to sclerotherapy, this meta-analysis could not demonstrate clearly the superiority of one technique over the other, because there was a moderate heterogeneity $\left(I^{2}=49 \%\right)$ among the studies included. We have no doubt that ligation is better than sclerotherapy, but the advantage of ligation may not be in the bleeding episode, but in the secondary prophylaxis with a faster and safer variceal eradication.

Sclerotherapy and vasoactive drugs combined were superior to sclerotherapy alone in regard to efficacy of bleeding control, overall rebleeding rate, and rebleeding rate from active bleeders in seven, six and four trials, respectively ( $>$ Fig. 5, $\triangleright$ Fig. 6, - Fig. 7). There is a compelling body of evidence that the combination of sclerotherapy and vasoactive drugs is more effective than sclerotherapy alone in hemorrhage control. This meta-analysis confirmed that with a highly significant statistical difference and a low heterogeneity among the studies ( 7 trials; RR of $\left.1.17 ; 95 \% \mathrm{Cl} 1.10-1.25 ; P<0.00001 ; I^{2}=25 \%\right)$. However, there 


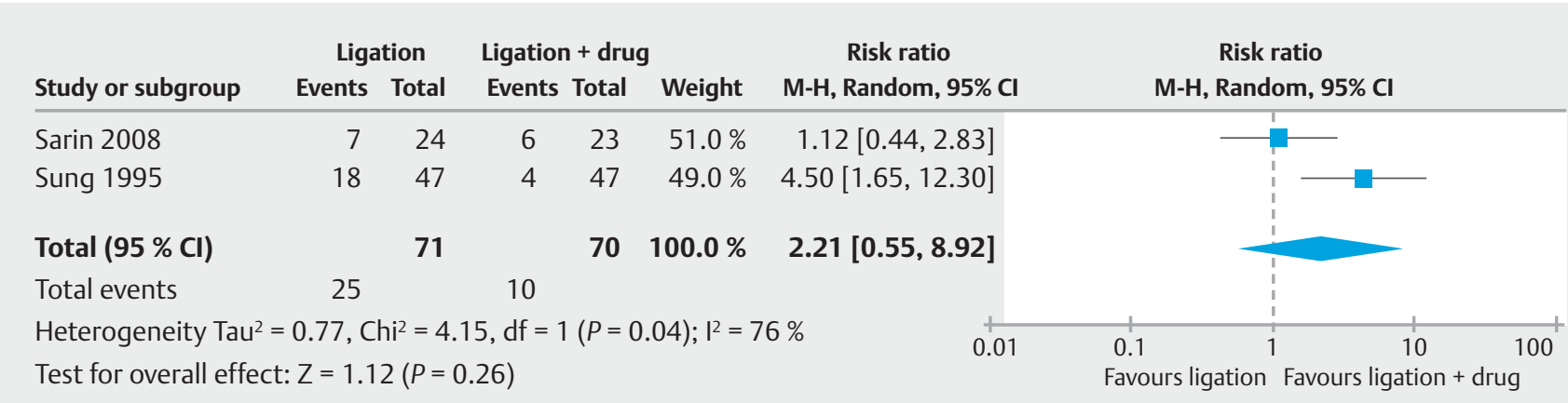

Fig. 8 Forest plot of risk ratio for overall rebleeding with ligation alone versus ligation and vasoactive drug.

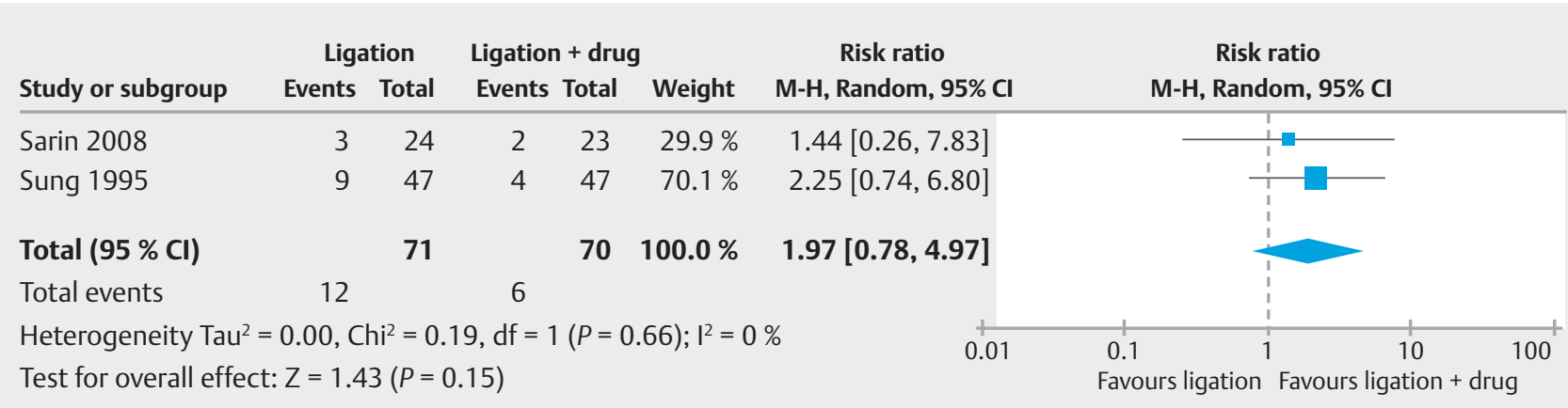

Fig. 9 Forest plot of risk ratio for in-hospital mortality with ligation alone versus ligation and vasoactive drug.

was no difference in respect to mortality in the meta-analysis and in any individual RCT. It is interesting to note that none of these studies were performed in North America (2 European, 1 Brazilian and 4 Asian trials).

Many previous trials and meta-analyses have shown that vasoactive drugs are better than placebo, vasoactive drugs are similar to sclerotherapy, and the combination of vasoactive drugs and sclerotherapy is superior to sclerotherapy alone [25, 47,48 ]. A recent meta-analysis [47] even compared therapeutic interventions for AVB with placebo, which has been unacceptable as a treatment option since the early $1990 \mathrm{~s}$.

Another technique that generated a meta-analysis and is not performed anymore is the combination of ligation and sclerotherapy. This therapy was abandoned due to a high incidence of side effects, which was confirmed by our study; nonetheless in this meta-analysis, it was demonstrated to be as effective as ligation alone in bleeding control, rebleeding, and mortality.

In this study, when we analyzed separately active bleeders at the moment of initial endoscopy, use of sclerotherapy with vasoactive drugs was superior to sclerotherapy alone. In 439 patients from four studies, combined therapy reduced rebleeding by $22 \%(95 \% \mathrm{Cl} 1.13-1.32)$ with no heterogeneity. We could not evaluate mortality in this subgroup of patients because the studies, when quoting mortality, did not state this outcome separately (they quoted mortality for both active and non-active bleeders).

Although most studies reported in the literature included patients with recent and ongoing hemorrhage, it should be em- phasized that therapies used after bleeding had spontaneously stopped will have their results overestimated. Active bleeding at endoscopy is a well-known risk factor for worse outcomes in patients with variceal as well as non-variceal bleeding [3]. Only six studies of the 36 analyzed included only patients with active variceal bleeding, four of them compared sclerotherapy with the combination of sclerotherapy and octreotide. The other 30 RCTs pooled together the results of the different treatments among active and non-active bleeders at time of endoscopy.

Notwithstanding we have done a meta-analysis with solely two studies comparing ligation plus vasoactive drug versus ligation alone, this is the only available meta-analysis grouping this treatment, which is recommended by AASLD, the American Society of Gastrointestinal Endoscopy (ASGE) and EASL guidelines as the gold standard in management of variceal bleeding (considered as level of evidence $1 \mathrm{a}$, grade $\mathrm{A}$ recommendation) [49-51]. ESGE has no current guideline about this issue. Although that recommendation is routinely used in clinical practice, just two Asian studies evaluated use of ligation plus vasoactive drugs in comparison to ligation alone [20,40] and another trial compared ligation plus octreotide versus octreotide alone [42].

In the study by Sung et al., ligation and somatostatin was highly superior to ligation alone in management of variceal bleeding. On the other hand, in the study by Sarin et al., published as an abstract, the combination of ligation and octreotide did not show an advantage over ligation alone. When performing a meta-analysis of both these studies, there was clearly 
no benefit of combination therapy in terms of rebleeding and mortality. It is important to note that no Western study evaluated the role of ligation plus vasoactive drug in treatment of AVB.

There was no study evaluating use of early TIPS in AVB included in this meta-analysis. The only study using early TIPS selected was excluded because all patients received ligation or sclerotherapy in the first 24 hours, before randomization [52].

As in every meta-analysis, comparison of studies may have been impaired by differing in-hospital follow-up, which in some studies is evaluated at 5 days and in others at 6 weeks. In this study, those data have been pooled together as overall mortality. Time until rebleeding occurred also varied among studies, ranging from 2 to 5 days and was considered as one sole group. Notably, we excluded patients with hepatocellular carcinoma, who comprise at least one-fifth of bleeders. However, this population of patients has a worse response to any treatment and should be evaluated separately.

Furthermore, we also excluded a few articles that were not published in English due to their unavailability, although their inclusion would not affect the final analysis. Other possible limitations of our study are the unclear risk for concealment of treatment allocation in 18 trials and high risk for blinding of participants/personnel in 10 trials. Meanwhile, the blinding of endoscopists and patients undergoing upper digestive endoscopy is impossible, as in studies involving surgical interventions. Moreover, only nine of 36 studies mentioned conflict of interest. In addition, prediction intervals indicated a significant amount of uncertainty on treatment effect sizes and direction for several of the meta-analytic comparisons performed, which means that many of the research questions addressed are still unanswered. Larger and well-designed trials are needed in this field.

On the other hand, studies using placebo as a treatment were not included because there are well-established treatments available for AVB.

During the last decade, mortality rates with acute variceal bleeds have decreased. Routine medical care varied with respect to use of diagnostic and/or therapeutic endoscopy, balloon tamponade, resuscitation policy, and antibiotic prophylaxis for spontaneous bacterial peritonitis.

\section{Conclusion}

In summary, the combination of sclerotherapy and vasoactive drugs is superior to sclerotherapy or vasoactive drugs alone in management of variceal bleeding. Ligation was better than sclerotherapy as a treatment option for variceal bleeding, although heterogeneity of the results may invalidate this assumption. Although society guidelines recommend the combination of endoscopic band ligation and vasoactive medications for treatment of AVB, this statement could not be evidenced in the literature.
Competing interests

Author J.P.L. is a proctor of Boston Scientific. The other authors declare no Conflict of Interests for this article.

\section{References}

[1] Ferguson JW, Tripathi D, Hayes PC. Review article: the management of acute variceal bleeding. Aliment Pharmacol Ther 2003; 18: 253 262

[2] Marot A, Trepo E, Doerig C et al. P Systematic review with meta-analysis: self-expanding metalstents in patients with cirrhosis and severe or refractory oesophageal variceal bleeding. Aliment Pharmacol Ther 2015; 42: $1250-260$

[3] Gross M, Schiemann U, Muhlhfer A et al. Meta-analysis: efficacy of therapeutic regimens in ongoing variceal bleeding. Endoscopy 2001; 33: $737-746$

[4] Copenhagen Esophageal Varices Sclerotherapy Project. Sclerotherapy after first variceal hemorrhage in cirrhosis. N Engl J Med 1984; 311 : $1594-1600$

[5] Bendtsen F, Krag E, Moller S. Treatment of acute variceal bleeding. Dig Liver Dis 2008; 40: 328-336

[6] Deltenre P, Trepo E, Rudler M et al. Early transjugular intrahepatic portosystemic shunt in cirrhotic patients with acute variceal bleeding: a systematic review and meta-analysis of controlled trials. Eur J Gastroenterol Hepatol 2015; 27: e1-9

[7] Guyatt G, Oxman AD, Akl EA et al. GRADE guidelines: 1 IntroductionGRADE evidence profiles and summary of findings tables. J Clin Epidemiol 2011; 64: 383-394

[8] Guyatt GH, Oxman AD, Vist GE et al. GRADE: an emerging consensus on rating quality of evidence and strength of recommendations. BM] 2008; 336: $924-926$

[9] Higgins JP, Thompson SG, Deeks JJ et al. Measuring inconsistency in meta-analyses. BMJ 2003; 327: 557-560

[10] Riley RD, Higgins JPT, Deeks J]. Research Methods \& Reporting: Interpretation of random effects meta-analyses. Br Med J 2011; 342: d549

[11] Westaby D, Hayes PC, Gimson AE et al. Controlled clinical trial of injection sclerotherapy for active variceal bleeding. Hepatology 1989; 9: $274-277$

[12] Shields R, Jenkins SA, Baxter JN et al. A prospective randomised controlled trial comparing the efficacy of somatostatin with injection sclerotherapy in the control of bleeding oesophageal varices. J Hepatol 1992; 16: $128-137$

[13] Stiegmann GV, Goff JS, Michaletz-Onody PA et al. Endoscopic sclerotherapy as compared with endoscopic ligation for bleeding esophageal varices. N Engl J Med 1992; 326: 1527-1532

[14] Laine L, el-Newihi HM, Migikovsky B et al. Endoscopic ligation compared with sclerotherapy for the treatment of bleeding esophageal varices. Ann Intern Med 1993; 119: 1 - 7

[15] Gimson AE, Ramage JK, Panos MZ et al. Randomised trial of variceal banding ligation versus injection sclerotherapy for bleeding oesophageal varices. Lancet 1993; 342: 391 - 394

[16] Sung J], Chung SC, Lai CW et al. Octreotide infusion or emergency sclerotherapy for variceal haemorrhage. Lancet 1993; 342: 637-641

[17] Planas R, Quer JC, Boix J et al. A prospective randomized trial comparing somatostatin and sclerotherapy in the treatment of acute variceal bleeding. Hepatology 1994; 20: 370-375

[18] Besson I, Ingrand P, Person B et al. Sclerotherapy with or without octreotide for acute variceal bleeding. N Engl J Med 1995; 333: 555560 
[19] Lo GH, Lai KH, Cheng JS et al. A prospective, randomized trial of sclerotherapy versus ligation in the management of bleeding esophageal varices. Hepatology 1995; 22: 466 - 471

[20] Sung J], Chung SC, Yung MY et al. Prospective randomized study of effect of octreotide on rebleeding from oesophageal varices after endoscopic ligation. Lancet 1995; 346: 1666 - 1669

[21] Hou MC, Lin HC, Kuo Bl et al. Comparison of endoscopic variceal injection sclerotherapy and ligation for the treatment of esophageal variceal hemorrhage: a prospective randomized trial. Hepatology 1995; 21: $1517-1522$

[22] Laine L, Stein C, Sharma V. Randomized comparison of ligation versus ligation plus sclerotherapy in patients with bleeding esophageal varices. Gastroenterol 1996; 110: 529-533

[23] Shiha G, Hamid M, El-Said SS et al. Octreotide infusion plus emergency sclerotherapy versus sclerotherapy alone for the control of bleeding oesophageal varices: A prospective randomized clinical trial. Mans Med J 1996; 26: 109-121

[24] Lo GH, Lai KH, Cheng JS et al. Emergency banding ligation versus sclerotherapy for the control of active bleeding from esophageal varices. Hepatology 1997; 25: $1101-1104$

[25] Avgerinos A, Nevens F, Raptis S et al. Early administration of somatostatin and efficacy of sclerotherapy in acute oesophageal variceal bleeds: the European Acute Bleeding Oesophageal Variceal Episodes (ABOVE) randomised trial. Lancet 1997; 350: 1495-1499

[26] Saeed ZA, Stiegmann GV, Ramirez FC et al. Endoscopic variceal ligation is superior to combined ligation and sclerotherapy for esophageal varices: a multicenter prospective randomized trial. Hepatology 1997; 25: $71-74$

[27] Shafqat F, Khan AA, Alam A et al. Band ligation vs endoscopic sclerotherapy in esophageal varices: a prospective randomized comparison. J Pak Med Assoc 1998; 48: 192 - 196

[28] Al Traif I, Fachartz FS, Al Jumah A et al. Randomized trial of ligation versus combined ligation and sclerotherapy for bleeding esophageal varices. Gastrointest Endosc 1999; 50: 1 -6

[29] de la Pena J, Rivero M, Sanchez E et al. Variceal ligation compared with endoscopic sclerotherapy for variceal hemorrhage: prospective randomized trial. Gastrointest Endosc 1999; 49: 417-423

[30] Djurdjevic D, Janosevic S, Dapcevic B et al. Combined ligation and sclerotherapy versus ligation alone for eradication of bleeding esophageal varices: a randomized and prospective trial. Endoscopy 1999; 31: 286-290

[31] Sivri B, Oksuzoglu G, Bayraktar Y et al. A prospective randomized trial from Turkey comparing octreotide versus injection sclerotherapy in acute variceal bleeding. Hepatogastroenterol 2000; 47: 168-173

[32] Farooqi JI, Farooqi RJ, Haq N et al. Treatment and outcome of variceal bleeding - A comparison of two methods. J Coll Phys Surg Pakistan 2000; 10: $131-133$

[33] Bildozola M, Kravetz D, Argonz J et al. Efficacy of octreotide and sclerotherapy in the treatment of acute variceal bleeding in cirrhotic patients. A prospective, multicentric, and randomized clinical trial. Scand J Gastroenterol 2000; 35: 419-425

[34] Escorsell A, Ruiz del Arbol L, Planas R et al. Multicenter randomized controlled trial of terlipressin versus sclerotherapy in the treatment of acute variceal bleeding: The TEST Study. Hepatology 2000; 32: 471 476

[35] Zuberi BF, Baloch K. Comparison of endoscopic variceal sclerotherapy alone and in combination with octreotide in controlling acute variceal hemorrhage and early rebleeding in patients with low-risk cirrhosis. Am J Gastroenterol 2000; 95: 768-771
[36] Patsanas T, Kousopoulou N, Kapetanos D et al. A randomized controlled trial comparing octreotide vs octreotide plus sclerotherapy in the control of bleeding and early mortality from esophageal varices. Ann Gastroenterol 2002: 153-157

[37] Shah HA, Muntaz K, Jafri W et al. Sclerotherapy plus octreotide versus sclerotherapy alone in the management of gastro-oesophageal variceal hemorrhage. J Ayub Med Coll Abbottabad 2005; 17: 10-14

[38] Chen WC, Lo Gh, Tsai Wl et al. Emergency endoscopic variceal ligation versus somatostatin for acute esophageal variceal bleeding. J Chin Med Assoc 2006; 69: 60-67

[39] Morales GF, Pereira Lima JC, Homos AP et al. Octreotide for esophageal variceal bleeding treated with endoscopic sclerotherapy: a randomized, placebo-controlled trial. Hepatogastroenterol 2007; 54: $195-200$

[40] Sarin SK, Kumar A, Jha SK et al. Combination of somatostatin plus endoscopic variceal ligation (EVL) is similar to EVL alone in control of acute variceal bleeding: a randomized controlled trial. Hepatology (Baltimore, Md.) 2008: 628a

[41] Liu JS, Liu J. Comparison of emergency endoscopic variceal ligation plus octride or octride alone for acute esophageal variceal bleeding. Chin Med J (Engl) 2009; 122: 3003 - 3006

[42] Ljubicic N, Biscanin A, Nikolic M et al. A randomized-controlled trial of endoscopic treatment of acute esophageal variceal hemorrhage: $\mathrm{N}$-butyl-2-cyanoacrylate injection vs. variceal ligation. Hepatogastroentero 2011; 58: $438-443$

[43] Luz GO, Maluf-Filho F, Matuguma SE et al. Comparison between endoscopic sclerotherapy and band ligation for hemostasis of acute variceal bleeding. World J Gastrointest Endosc 2011; 3: 95-100

[44] Ximing W. Treatment experience of esophageal varices ligation in control of acute variceal bleeding. J Gastroenterol Hepatol 2013; 28: 774

[45] Sahu P, Kar P, Kumar KS. Endoscopic ligation compared with sclerotherapy for treatment of bleeding esophageal varices in decompensated cirrhotics. Indian | Gastroenterol 2014; 33: A53 - 54

[46] Mansour L, El-Kalla F, El-Bassat $\mathrm{H}$ et al. Randomized controlled trial of scleroligation versus band ligation alone for eradication of gastroesophageal varices. Gastrointest Endosc 2017; 86: 307 - 315

[47] Wells M, Chande N, Adams P et al. Meta-analysis: vasoactive medications for the managementof acute variceal bleeds. Aliment Pharmacol Ther 2012; 35: $1267-1278$

[48] D’Amico G, Pagliaro L, Pietrosi G et al. Emergency sclerotherapy versus vasoactive drugs for bleeding oesophageal varices in cirrhotic patients. Cochrane Database Syst Rev 2010; 17: CD002233

[49] de Franchis R. Baveno V Faculty. Expanding consensus in portal hypertension. Report of the Baveno VI Consensus Workshop: stratifying risk and individualizing care for portal hypertension. J Hepatol 2015; 63: $743-752$

[50] Garcia-Tsao G, Abraldes JG, Berzigotti A et al. Portal hypertensive bleeding in cirrhosis: Risk stratification, diagnosis, and management: 2016 practice guidance by the American Association for the Study of Liver Diseases. Hepatology 2017; 65: 310-335

[51] American Society for Gastrointestinal Endoscopy. The role of endoscopy in the management of variceal hemorrhage. Gastrointest Endosc 2014; 80: $221-227$

[52] Garcia-Pagan JC, Caca K, Bureau C et al. Early use of TIPS in patients with cirrhosis and variceal bleeding. N Engl J Med 2010; 362: 2370 2379 